\title{
Stroke Survivors' Experiences of Early Person- Centered Rehabilitation at Home - Living in Sparsely Populated Areas
}

\author{
Birgitta Nordström $^{1,2 *}$, Ann-Charlotte Kassberg ${ }^{1,2}$ and Sarianne Wiklund Axelsson ${ }^{1}$ \\ ${ }^{1}$ Department of Health Science, Luleå University of Technology, Luleå Sweden \\ ${ }^{2}$ Department of Development and Research, Region Norrbotten, Luleå, Sweden
}

${ }^{\star}$ Corresponding author: Birgitta Nordström, (Reg PT, PhD) Department of Health Science, Luleå University of Technology, and Department of Development and Research, Region Norrbotten, Luleå, Sweden; Tel: +46 9202846 91; E-mail: Birgitta.Nordstrom@norrbotten.se

Received: September 17, 2020; Accepted: September 28, 2020; Published: October 20, 2020

\begin{abstract}
Aim: The aim was to illuminate the situation of patients with stroke in sparsely populated areas and their experience of person-centred rehabilitation at home.

Methods: Fourteen persons with stroke who had received Early Supported Discharge home- rehabilitation following stroke were interviewed. The data were analyzed with a qualitative content analysis method.

Results: The analysis resulted in one overall theme: Living a life with a new version of me 2.0, built up from three categories: A new strengthen sense of self, Being at home creates trust and self-management and Environmental factors essential for rehabilitation at home.

Conclusion: The results exposed that early home rehabilitation in sparsely populated area following stroke influences the person's possibilities to return to the life they lived before. Living a life with the new version of me 2.0 includes conditions related to prerequisites of own empowerment and the importance of both relativities and professionals.
\end{abstract}

Keywords: Early supported discharge, Home, Multidisciplinary team, Person-centered rehabilitation, Rehabilitation, Stroke

Stroke is an important cause of disability and mortality worldwide $[1,2]$. In Sweden, approximately 25,000-30,000 are affected by stroke annually and stroke is one of the major causes of hospital admissions. People with stroke in the north of Sweden can be offered home-based rehabilitation, also known as Early Supported Discharge (ESD). Stroke patients may therefore be discharged from inpatient care to their home, if they meet the functional, cognitive and social criteria for ESD. Early rehabilitation at home with a multidisciplinary team is recommended for patients with minor to moderate symptoms after a stroke $[3,4]$. A systematic review evaluated the effectiveness of home vs. centre based rehabilitation and found that interventions should shift towards more home-based rehabilitation following stroke [5]. It has also been reported that persons with stroke often select homebased rehabilitation, when getting the option [6].

Rehabilitation at home stimulates the patient to participate actively in their rehabilitation and set goals for the future [7]. Rehabilitation at home also improves patient satisfaction and the number of days in hospital are reduced by several days [4,8]. Although, a stroke often causes motor impairments and a range of highly variable cognitive impairments [9-11]. The first year is a challenging for both stroke patients and informal caregivers $[12,13]$. The patient may suffer negative psychosocial effects because of the body being unreliable and the patient's self-identity, role and social relations may also be negatively affected $[14,15]$. A person with stroke may have an altered life instead of going back to life as it was before the stroke. The altered life may have an impact on the person's capacity to learn and adapt to a change in the environment [16]. Overall, a person-centred rehabilitation needs to include biopsychosocial and spiritual aspects, preferences, experience's and the right to make decisions about one's treatment $[17,18]$. It is about respecting, differences and deviation and having an inclusive attitude to the ways people view their own embodiment [19]. Living in a sparsely populated area, includes specific challenges such as long distances to receive rehabilitation. These conditions place high demands on the person, family members and their social network. Rehabilitation at home enables adaptation of the environment and provides opportunities for the patient to practice skills that are important for them. There are no studies regarding stroke patient's own perspective, of undergoing home-based rehabilitation in sparsely populated areas from true person-centred perspective [20]. Such knowledge may support health care providers to develop individual interventions at home and support transition from rehabilitation units to the home in this specific area. 


\section{Context}

The study involved patients in two municipalities in the northernmost county in Sweden. Norrbotten comprises about a quarter of the land area of Sweden but has only 250000 inhabitants. Most of the participants in this study live in sparsely populated areas with long distance to facilities where rehabilitation is available.

\section{Aim}

The aim was to illuminate the situation of patients with stroke in sparsely populated areas and their experience of person-centred rehabilitation at home.

\section{Method}

\section{Participants}

Fourteen stroke patients participated in the study. Interviews were held with 8 women and 6 men with an average age of 78 years (Table 1 ). The inclusion criteria's were that;(i) the person had a first time injury from a stroke, (ii) the person had received home based rehabilitation through the team from the hospital in northern Sweden; (iii) at least three months had elapsed since the person had the stroke, (iv) the person was able to share his/her experiences during an interview.

\section{Study Design}

A qualitative interview study with a content analysis approach was performed [21].

\section{Procedures}

To obtain participants the first author contacted the professionals in stroke rehabilitation at the hospital. A purposive sampling was made and the patients who fulfilled the inclusion criteria were selected by health care professionals at the rehab units. The persons who were interested received more information about the study from the first author. The patients were given oral and written information about the study and thereafter, written consent was given by the patient. The study was approved by the Ethical Review Board in Umeå, Sweden (Reg. no. 2017/512-31).

Table 1: Description of the participants in the study.

\begin{tabular}{|l|c|c|c|c|c|}
\hline Participant & Sex & Age (years) & Marital status & Accommodation & Severity of stroke \\
\hline 1 & Female & 83 & Cohabitating & Apartment & Mild \\
\hline 2 & Female & 53 & Single & House & Moderate \\
\hline 3 & Female & 77 & Cohabitating & House & Moderate \\
\hline 4 & Female & 76 & Cohabitating & House & Moderate \\
\hline 5 & Female & 74 & Single & Apartment & Moderate \\
\hline 6 & Female & 53 & Cohabitating & House & Moderate \\
\hline 7 & Female & 85 & Single & Apartment & Moderate \\
\hline 8 & Male & 88 & Single & House & Mild \\
\hline 9 & Male & 74 & Cohabitating & Apartment & Severe \\
\hline 10 & Female & 69 & Cohabitating & House & Moderate \\
\hline 11 & Male & 90 & Single & House & Moderate \\
\hline 12 & Male & 83 & Cohabitating & Apartment & Mild \\
\hline 13 & Male & 76 & Cohabitating & House & Moderate \\
\hline 14 & Male & 82 & Cohabitating & House & Moderate \\
\hline
\end{tabular}

\section{Program}

The ESDs were carried out from one hospitals in northern Sweden. The goals for the rehabilitation were established in collaboration between the professionals and the patient. An individually designed intervention plan was constructed and all interventions were performed in patients' homes. The rehabilitation team consisted of: occupational therapist, physiotherapist, counselor, physician and nurse. The intensity and length of the rehabilitation period were based on the patients' needs and progress.

\section{Data Collection}

Individual interviews were conducted in the participants' homes by the first author who was not involved in the rehabilitation. The interview started with the question "Could you please tell me what happened when you had your stroke"? The interviews were semistructured and covered a variety of topics (Table 2). The participants were encouraged to talk about their experiences regarding their stroke. The narration was supported with questions such as "Can you please explain more?" or "What happened then?" Each interview lasted about 30 minutes.

Table 2: Main topics of the interview.

\begin{tabular}{|l|}
\hline 1. The day you had your stroke \\
\hline 2. Perceived consequences of the stroke \\
\hline 3. Thoughts about rehabilitation at hospital \\
\hline 4. Thoughts about rehabilitation at home \\
\hline 5. Any other topics not already covered \\
\hline
\end{tabular}

\section{Data Analysis}

The verbatim transcriptions were analyzed using qualitative content analysis inspired by Graneheim and Lundman [21] to discover the underlying meaning of the text. All authors were involved in all steps of the analysis of the text. Each interview text was read through to gain an initial understanding of the material as a whole. As a first step, the interview text was divided into meaning units related to the aim of the study. Thereafter the meaning units were condensed using a description close to the text to maintain the meaning of the original text (Table 2). The condensed meaning units were coded and sorted into different categories identified through discussion and reflection among the authors. Throughout the analysis, the authors went back to the original text to validate the findings in the categories.

\section{Results}

The analysis of the interviews resulted in one overall theme: Living my life with a new version of me 2.0. The theme represents the participants' development of their empowerment by having rehabilitation at home. The participants described how the stroke had changed them and how the rehabilitation was customized to suit their individual needs. Rehabilitation at home strengthened them as a person and made them take greater responsibility for their rehabilitation. The contextual factors such as collaboration and partnership with others were also highlighted. This theme was made 
up of three categories (1) A new strengthened sense of self, (2) Being at home promotes confidence and self-management, (3) Contextual factors are essential for rehabilitation at home. The categories with underlying sub-categories are all presented in Table 3.

\section{Category 1: A New Strengthened Sense of Self}

The category: A new strengthened sense of self was created from the subcategories; Time for reflection; Increased confidence in one's own ability and Person-centered approach. Rehabilitation at home gave the participants a sense of mental strength and stamina and the participants felt involved in their own rehabilitation and they expressed greater self-determination (Table 4).

\section{Category 1:1 Time for Reflection}

The participants reflected over how their functionality had changed. One participant said: "Maybe my brain needed to rest after the stroke because everything was gone. Oh, my God! I had been working with economy and now everything was gone?" (person 14). Initially, the participants were overwhelmed that they had survived, now they were trying to return to their life as it was before. They talked about listening to signals from the body and not be controlled by all the "musts" "I started to plan in my head...thinking about the things I had to do...but I have tried to let thoughts like that go away and instead relax, just consciously stop thinking about all demands" (person 8). Another participant talked about struggling with thinking in a different way when her power was limited: "You see, I have not cut the grass yet which I usually do but I thought ... what beautiful flowers, there's nothing wrong with just looking at the flowers" (person 6). They reflected on their own role when the rehabilitation was performed at home. Some participants reflected on the possibility of seeing a counsellor if needed. One participant described the general anxiety he experienced following his stroke: "I suffer from anxiety at times and I have medication for that but I don't think it works very well...it is latent all the time and I'm not worried about anything specific ... it's general anxiety" (person 11).

\section{Category 1:2 Increased Confidence in One's Own Ability}

The participants described how the professionals encouraged them to do things they did not believe they were able to do. "Rehabilitation at home is worth so much. My husband said to me: 'You must use the wheelchair when you are at home and you must not walk without a cane'. Then the occupational therapist and physiotherapist came home and put a walking belt on me and said: We are not going to hold you because you can manage yourself now" (person 1). The same person described how the professionals literally lifted her from the wheelchair to an upright position on her feet. Another participant felt that the stroke had made her feel like he was not good enough for anything. However, she also expressed how she felt increasingly better over time. "The professionals told me 'You can do everything by yourself' (person 2). The professionals seemed to have the ability to get the participants to challenge their boundaries and feel more confident about their abilities. "I held on with my left hand and it worked out so I have walked up and down several times and that made my self-confidence coming back and I dared to let go" (person 1). Another participant expressed similar thoughts: "Being in control of my own rehabilitation gives mental strength" (person 11).

\section{Category 1:3 Person Centered Approach}

The participants emphasized that they were seen as being the experts on themselves and what was important for them. "I felt that they saw me... I felt that I was important. I am a V.I.P ...so they are coming to my home" (person 1). The feeling of being seen and acknowledged as a person was mentioned many times in the interviews. "They [health care professional]asked me what was important to me and how I wanted things to be, I said that I wanted to be able to do things that I had done before" (person 6). Another participant expressed it as follows: "At home, you are in the right environment and you can see what you need to train so you can manage at home... what is best for me" (person 12). The analysis revealed that the patients really appreciated being asked what was important to them. The support from the professionals was invaluable in the patients' efforts to become independent and return to a good life. However, sometimes it was necessary to limit the amount of training. "She said it was enough for me to train three times a week because it wasn't good for me to exercise too much, but I'm that kind of person, unfortunately" (person 4).

\section{Category 2: Being at Home Promotes Confidence and Self- Management}

This category was made up of the following subcategories: Goal directed training of body functions and activities in a real

Table 3: Illustration of the analysis process from meaning unit to category.

\begin{tabular}{|l|l|l|}
\hline Meaning unit & Condensed meaning unit & Code \\
\hline $\begin{array}{l}\text { Because I continually told them "I can do this now", they could see that I could do this } \\
\text { (walk down the steps to the basement). And I felt a sense of achievement and that my self-- } \\
\text { confidence was coming back and I dared to let go }\end{array}$ & $\begin{array}{l}\text { Demonstrating one's progress and } \\
\text { feeling growing self-confidence }\end{array}$ & Feeling competent \\
\hline
\end{tabular}

Table 4: Illustration of the results.

\begin{tabular}{|c|c|}
\hline Theme: Living my life with the new version of me 2.0 & \\
\hline Category & Subcategory \\
\hline A new strengthened sense of self & $\begin{array}{ll}\text { - } & \text { Time for reflection } \\
\text { - } & \text { Increased confidence in one's own ability } \\
\text { - } & \text { Person-centred approach }\end{array}$ \\
\hline Being at home promotes confidence and self-management & $\begin{array}{ll} & \text { Goal directed training of body functions and activities in a real environment } \\
\text { - } & \text { Development of new strategies } \\
\text { - } & \text { Empowerment and own responsibility }\end{array}$ \\
\hline Contextual factors are essential for home rehabilitation & $\begin{array}{l}\text { - } \quad \text { Partnership between clients, relatives and professionals strengthens the outcome } \\
\text { - }\end{array}$ \\
\hline
\end{tabular}


environment, Development of new strategies and Empowerment and own responsibility. The category revealed that home rehabilitation supported the participants' self-efficacy. The support from professional healthcare providers was perceived as a privilege. Performing activities and exercising in one's own home gave a feeling of harmony and security. The participants also talked about taking responsibility themselves, as well as being given alternatives from the healthcare professionals.

\section{Category 2:1 Goal Directed Training of Body Functions and Activities in a Real Environment}

The participants decide what goals were most important for them and together with the professionals, they drew up a feasible schedule: "The first plan is to manage to walk to the grocery store, even if they are walking behind me with the wheelchair...however, I will at least be able to walk there. Then I will try to be more sociable and part of the community again" (person 4). Rehabilitation at home was described as exercises aiming to improve balance, the ability to walk, training of hand function, training the memory and so on. The participants talked about how they trained different body functions with and without assistive devices. "We practiced throwing a ball to each other; we trained our sense of balance. I had a walker that I had borrowed and taken home; I think I used it twice" (person 8). Regarding the home environment one participant said "I think it's different and better when I'm at home because I am in control of things myself". (person 8). Rehabilitation at home was seen as being a good start but one participant said that training together with others was even better "It is nice to share experiences with others" (person 5). Not all participants understood the purpose of having rehabilitation at home. One participant said that rehabilitation could be more effective at hospital while another thought that it was enough with natural recovery: "Yes, it [the function] has returned and it's getting better and better so I don't know if there is any point training any more"(person 14). It came up that it was difficult for the participants to know whether the staff came from the municipality or from the county council and what the training they should do consisted of: "The girls helped me to train there [at the hospital] and they came home and watched me exercising... yes, those straps, I was supposed to pull them 40 times and I said that I usually pulled them 140 times" (person 9).

\section{Category 2:2 Development of New Strategies}

Many participants described how they had to create new strategies after their body functions had changed after the stroke. "I was wondering if I would be able to use my baking machine again. I have it in a wardrobe ... but then I found out that if I take my walker .... I can lift it up on it, I think I will manage that and then I can roll the walker to the kitchen and lift the machine up on the worktop in the kitchen" (person 2). The participants also expressed the importance of being able to rest after exercising and that was easier at home. "At home, I am able to rest whenever I want" (person 3). If they had to go to the hospital for rehabilitation, it would have entailed long, tiring journeys by car or bus. When they have rehabilitation in their home, new strategies developed based on the needs in daily life. Several participants pointed out the importance of being independent in daily activities at home. They described how they had trained and developed strategies for being able to perform activities at home "I had to practice grabbing and holding things with my left hand. Then I knew I would be able to chop vegetables" (person 4 ). Some participants mentioned that new strategies arose when they got new assistive devices.

Walking with a walker required space which implied changes in the environment."When I came home, it was so cluttered...I had several armchairs. I thought, oh dear, how I can walk here? Now I have rearranged things"... (person 6 ).

\section{Category 2:3 Empowerment and Own Responsibility}

The participants talked about being in charge of their own rehabilitation and responsible for ensuring that the exercises were done. One participant said:"The purpose of rehabilitation is to do the exercises by myself. I make a schedule and report what I have done and also what I should do" (person 11). At the start of the rehabilitation process, it was obvious that the participants did not have much confidence and faith in their own abilities. Some participants described they were afraid of falling as a result of their deteriorated balance. Being able to train body functions with the support of the professionals was described as a valuable contribution to improved function and thus it increased the participants' confidence in their own ability. One of the participants expressed it like this: "They have taken a real interest in me, this is what I can do now and I am able to say: We don't need to train that, I can already do it. Being able to tell them that I have filled the dishwasher and that I try to train my left hand all the time by, for instance, hanging up laundry, it has not been so easy, clothes pegs and my fingers get stuck everywhere" (person 1).

\section{Category 3: Contextual Factors are Essential for Home Rehabilitation}

This category is made up of the subcategories: Partnership between clients, family members and professionals strengthens the outcome and collaboration between all parties is a prerequisite for successful rehabilitation. The category represents factors which the participants mentioned had had an impact on the implementation of rehabilitation in the home, for example, support from family members and social and professional support.

\section{Category 3:1 Partnership between Clients, Family Members and Professionals Strengthens the Outcome}

The participants were happy to be able to return home after a period at hospital but they described being tired and in need of various kinds of help, for example, help with household chores, cooking, shopping and fixing things in the home. Some of the participants had help from municipal homecare services. Professionals from the healthcare sector were important because, in addition to rehabilitation, they provided security and safety. Many participants said they had support from family members and friends as well. One participant said: "After all, I have had a cohabitant who has done everything" (person 13). One participant described how much she appreciated the help she had been given by her daughter, both with cooking and help with going to the toilet during the night. "My greatest happiness was when I was able to get in and out of bed at night and go to the toilet by myself so my 
daughter no longer had to get up twice a night to help me" (person 4). The participants also talked about the importance of taking advantage of the professionals' competence and working together with them to get as much as possible out of the rehabilitation at home: "The professionals knew what kind of rehabilitation I needed, namely, training hand functions and balance" (person 3).

\section{Category 3:2 Collaboration between all Parties is a Prerequisite for Successful Rehabilitation}

Some participants had a number of different healthcare providers involved in their care and rehabilitation, for example, both municipal and county council professionals. Some of the participants also had municipal homecare with staff who were involved in walking exercises, for example. Sometimes, the different cultures and different laws, rules, and budgets could clash and therefore, a coordinated individual plan was drawn up with all the organizations' involved and the patient was able to express his/her own desires and needs: "We had a meeting at the hospital before I was discharged and sent home... so we knew that they (the rehabilitation professionals) were coming to our home and we had some information about that but ..." The participant who had his partner as a prompter because of verbal difficulties said: "It has been difficult, they (the homecare professionals) have not been involved... it is stated in the decision taken by the care assistance officer... the help given was sporadic and they asked: Do you want to walk with the walker?" but there was no regularity with that either... it did not work" (person 10). Another participant said that it worked very well when he came home: "I don't remember exactly but as far as I can remember, the homecare services worked well right from the start. They came in the morning to see if I was alive: I learned to walk, leave the ... walk without support"(person 7).

\section{Discussion}

The main results revealed that rehabilitation at home following a stroke helped the patients to become a new version of themselves, including a strengthened sense of self and greater confidence with regard to self-management. The results showed that contextual factors were perceived as being significant for successful home rehabilitation. The results indicated that the stroke and the rehabilitation given at home after the stroke influenced the participant's thoughts about who they were and who they wanted to become. Many of the participants reflected on how their life had changed and they thought a lot about what is really important in life Was it a matter of being independent and having a body with the same functionality as before the stroke or was it something else? In rehabilitation, the physical body is referred to in medical terms which can lead to all the other values of the body and its potential being neglected [19]. A human being is not only capable of performing motor tasks through bodily processes; humans are those processes and that is what constitutes a person. Together, the motor system, the proprioceptive system and the sensorial system provide bodily functions, and at the same time form the foundation of one's self-identity [22]. During the period of rehabilitation at home, the participants highlighted the support provided by the professionals and how it strengthened their confidence in their own capability. Another outcome was that several participants pointed out that the professionals had encouraged them to believe in their own abilities.
The participants in the study described that they had been seen as playing an active role in their own rehabilitation which is in line with the ICF where patient participation is a core component of rehabilitation as well as the person (patient) centered approach [2325]. In the person/patient centered approach, the professionals are supposed to confirm the experiences and interpretation of illness that the patients depict. The approach is based on mutual respect and understanding, and the promotion of patients' right to selfdetermination [26]. The goal of person centered care is to provide medical care and rehabilitation that is concordant with the patients' cultural values, needs and preferences. Living in a rural areas brings challenges that differ from those when living in urbanized areas. Public transport is infrequent, the distances to health care and other services can be considerable. Therefore, early stroke rehabilitation at home is an opportunity for persons living in rural areas to receive high quality rehabilitation, but it also demands efforts from relatives, friends and the surrounding environment. It is also an important factor linked to the quality of personal, professional and organizational relationships [27]. Patient centered care is now reported as one of six elements of highquality care in the Institute of Medicine's quality chasm report [28]. According to NICE guidance regarding a safe rehabilitation after stroke a personcentered approach is recommended. Individualized goal setting is also recommended as well as involving the patient and his/her family members or careers in discussions [29].

The participants appreciated having rehabilitation at home. For them, it was positive to have the opportunity to train in their home environment and to be able to rest when they needed to. Coming home, the participants had to decide which functions they felt were the most important for them to train. A goal directed approach to training is meant to increase the person's ability to be engaged in meaningful activities [30]. The person's ability, the goal and the environment are the core components in how movement patterns emerge [31]. This is in line with occupational therapy knowledge which means that performance of activities is an interaction between the person, the environment and the occupation [32,33]. This coincides well with the purpose of home based rehabilitation after a stroke where the participants had customized training which matched the goals the patients had chosen in the environment where they were living their everyday lives. A study in Lancet showed that for therapy-based rehabilitation for persons after a stroke, living at home could reduce the risk of deterioration in ability to perform activities in daily life [34]. It is also concluded that patients are more likely to improve if they practice tasks at home in convenient blocks of 20 minutes a few times a day when they select tasks they are motivated to add to their daily activities. Persons who had rehabilitation at home even decreased sitting time, added more steps and walking time compared with the time when they were in hospital [31].

Rehabilitation at home highlighted the need for new strategies for coping with tasks that had been easy to do previously. The concept of self-management, which is a process that develops skills and strategies to manage the physical, psychological and social effects of chronic illness $[35,36]$ corresponds well with this. Self-efficacy is important in the construction of self-management, which emphasizes how important it is that the individuals believe in their own abilities [37]. 
According to a study, stroke survivors and physiotherapists view the meaning of self-management as being about 'doing things for yourself and 'looking after yourself', 'taking an active role in rehabilitation' and 'managing one's recovery and health'. The individual's role of taking responsibility was also highlighted in the study [38]. A stroke often has an impact on the health and quality of life of many persons, not only the person who experienced the stroke. The family members, friends and people who care for the survivor may be involved. According to Lou et al, patients in collaboration with their partners willingly took responsibility for their own rehabilitation regarding physical, emotional and biographical recovery [39]. Even if they saw themselves as being responsible for the rehabilitation they also pointed out that the professionals in the rehabilitation team were a valuable safety net who provided them with information, advice and support for their recovery process. These experiences are in line with the experiences of the participants in our study who also valued their family and home rehabilitation team highly. It is important to identify the needs of the family members taking care of the stroke survivors at home. Doing so will help to develop a greater understanding of home felt needs and the home rehabilitation for stroke survivors. Fulfilling the home felt needs of family members may promote the successful home rehabilitation of stroke survivors. To achieve integration and effectiveness, collaboration among professionals, family members and organizations is essential. The prerequisites are both a well performing team and an integrated rehabilitation. The participants in this study revealed that they were not always aware of which professionals were involved in the rehabilitation but it was not important to them either. What was important was collaboration and the partnership between all the parties the patients interacted with in different contexts. A wellperforming team is based on interprofessional communication of clear roles and goals, shared team identity, team tasks, interdependence, integration and shared responsibility [40]. Integrated rehabilitation means health professionals working together with patients and family members, using a systematic approach to provide personcentered rehabilitation with interconnectedness of interventions of rehabilitation to address the whole person [40].

\section{Methodological Considerations}

Throughout the analysis of the interviews, all authors worked together. The authors moved between the original and the analysed data during the whole process which is in line with Morse et al. [41]. Who highlighted the importance of focusing on the processes of ensuring rigor during the study, rather than waiting until the end when it might be too late to correct errors. The participants were chosen through a strategic selection with the aim of gaining an insider perspective from the stroke survivors. The aim of qualitative studies is to describe different variations of an area, not to generalize a specific phenomenon from a selection to a wider population. To achieve transferability, the authors provided a description of the participants, the context, data collection and the analysis process as well as appropriate quotations [21]. However, one limitation of the study was not known which part of home rehabilitation was the most important for the perceived positive outcome. On the other hand, this was not the aim of the study, which could be a suggestion for further studies.

\section{Conclusion}

In conclusion, the consequences of a stroke contributed to the development of a new life, version 2.0. This study showed that person-centered ESD rehabilitation at home after a stroke enhanced the person's self-management, empowerment and strategies. Social support from family members and guidance from a multi professional team were essential for home rehabilitation. ESD rehabilitation at home following a stroke strengthened important psychosocial aspects as well as independence in different biomechanical activities as a first glance.

\section{Acknowledgments}

We would like to thank all the participants in this study. We also thank Region Norrbotten, Sweden for financial support.

Declaration of interest: The authors report no declaration of interest.

\section{References}

1. Feigin VL, Krishnamurthi R (2011) Stroke prevention in the developing world. Stroke 42: 3655-58. [crossref]

2. Thrift AG, Thayabaranathan T, Howard G, Howard VJ, Rothwell PM, et al. (2017) Global stroke statistics. Int J Stroke12: 13-32. [crossref]

3. Langhorne P, Bernhardt J, Kwakkel G (2011) Stroke rehabilitation. The Lancet 377: 1693-1702.

4. Langhorne P, Dey P, Woodman M, Hamrin E, Kalra L, et al. (2005) Is stroke unit care portable? A systematic review of the clinical trials. Age and Ageing 34: 324-30.

5. Hillier S, Inglis-Jassiem G (2010) Rehabilitation for community-dwelling people with stroke: Home or centre based? A systematic review. Int J Stroke 5: 178-86. [crossref]

6. Weiss Z, Snir D, Zohar R, Klein B, Eyal P, et al. (2004) Allocation and preference of patients for domiciliary or institutional rehabilitation after a stroke. Int J Rehabil Res 27: 155-58. [crossref]

7. Reunanen MA, Järvikoski A, Talvitie U, Pyöriä O, Härkäpää K (2016) Individualised home-based rehabilitation after stroke in eastern $\mathrm{F}$ inland-the client's perspective. Health Soc Care Communit 24: 77-85. [crossref]

8. Fearon P, Langhorne P, Trialists ESD (2012) Services for reducing duration of hospital care for acute stroke patients. Cochrane Database Syst Rev. [crossref]

9. Gray V, Rice CL, Garland SJ (2012) Factors that influence muscle weakness following stroke and their clinical implications: A critical review. Physiother Can 64: 415-26. [crossref]

10. Hoffmann T, Bennett S, Koh C, McKenna K (2010) A systematic review of cognitive interventions to improve functional ability in people who have cognitive impairment following stroke. Top Stroke Rehabil 17: 99-107. [crossref]

11. Patel M, Coshall C, Rudd AG, Wolfe CD (2003) Natural history of cognitive impairment after stroke and factors associated with its recovery. ClinRehabil 17: 15866.

12. Jönsson A, Delavaran H, Iwarsson S, Ståhl A, Norrving B, et al. (2014) Functional status and patient-reported outcome 10 years after stroke: The lund stroke register. Stroke 45: 1784-90.

13. Green TL, King KM (2010) Functional and psychosocial outcomes 1 year after mild stroke. JJ Stroke Cerebrovasc Dis 19: 10-16. [crossref]

14. Merleau-Ponty M (2013) Phenomenology of perception. London: Routledge.

15. Pallesen H (2014) Body, coping and self-identity. A qualitative 5-year follow-up study of stroke. Disabil Rehabil 36: 232-41. [crossref]

16. Taule T, Råheim M (2014) Life changed existentially: A qualitative study of experiences at 6-8 months after mild stroke. Disabil Rehabil 36: 2107-19. [crossref]

17. McCormack B (2003) A conceptual framework for person-centred practice with older people. Int J Nurs Pract 9: 202-209. [crossref] 
18. Morgan S, Yoder LH (2012) A concept analysis of person-centered care. J Holist Nurs 30: 6-15. [crossref]

19. Nicholls DA, Gibson BE(2010) The body and physiotherapy. Physiother Theory Pract 26: 497-509. [crossref]

20. Yun D, Choi J (2019) Person-centered rehabilitation care and outcomes: A systematic literature review. Int J Nurs Stud 93: 74-83.

21. Graneheim UH, Lundman B (2004) Qualitative content analysis in nursing research: Concepts, procedures and measures to achieve trustworthiness. Nurse Educ Today 24: 105-12. [crossref]

22. Gallagher S, Zahavi D (2013) The phenomenological mind. Routledge.

23. World Health Organization (2009) International classification of functioning, disability and health (ICF); 2001. Geneva: WHO.

24. Buhl I, Pallesen H (2015) Early rehabilitation of patients with severe acquired brain injury: Strategies to promote participation. Scand J OccupTher 22: 181-195. [crossref]

25. Angel S, Kirkevold M, Pedersen BD (2011) Rehabilitation after spinal cord injury and the influence of the professional's support (or lack thereof). J ClinNurs 20: 1713-22. [crossref]

26. McCance T, McCormack B, Dewing J (2011) An exploration of person-centredness in practice.

27. Epstein RM, Street RLJr (2011) The values and value of patient-centered care. Ann Fam Med 9: 100-03. [crossref]

28. Wolfe A (2001) Institute of medicine report: Crossing the quality chasm: A new health care system for the 21st century. Policy, Politics, \& Nursing Practice 2: 233-235. [crossref]

29. Dworzynski K, Ritchie G, Fenu E, MacDermott K, PlayfordED, et al. (2013) Rehabilitation after stroke: Summary of NICE guidance. BMJ 346: f3615. [crossref]

30. Mastos M, Miller K, Eliasson A, Imms C (2007) Goal-directed training: Linking theories of treatment to clinical practice for improved functional activities in daily life. ClinRehabil 21: 47-55. [crossref]
31. Simpson DB, Breslin M, Cumming T, Zoete SD, Gall SL, et al. (2018) Go home, sit less: The impact of home versus hospital rehabilitation environment on activity levels of stroke survivors. Arch Phys Med Rehabil 99: 2216-2221. [crossref]

32. Kielhofner G (2008) Model of human occupation. theory and application. 4th ed. Baltimore: Lippincott Williams \& Wilkins (eds.).

33. Persson D, Erlandsson L, Eklund M, Iwarsson S (2001) Value dimensions, meaning, and complexity in human occupation-a tentative structure for analysis. Scand J Occup Ther 8: 7-18.

34. Legg L, Langhorne P (2004) Rehabilitation therapy services for stroke patients living at home: Systematic review of randomised trials. The Lancet 31: 352-6. [crossref]

35. Hinder S, Greenhalgh T (2012)" This does my head in". ethnographic study of selfmanagement by people with diabetes. BMC Health Services Research 12: 83.

36. Lorig KR, Holman HR (2003) Self-management education: History, definition, outcomes, and mechanisms. Ann Behav Med 26: 1-7. [crossref]

37. Bandura A (2006) Guide for constructing self-efficacy scales. Self-efficacy beliefs of adolescents 5: 307-337.

38. Sadler E, Wolfe CD, Jones F, McKevitt C (2017) Exploring stroke survivors' and physiotherapists' views of self-management after stroke: A qualitative study in the UK. BMJ Open 7:e011631-2016-011631. [crossref]

39. Lou S, Carstensen K, Møldrup M, Shahla S, Zakharia E, et al. (2017) Early supported discharge following mild stroke: A qualitative study of patients' and their partners' experiences of rehabilitation at home. Scand J Caring Sci 31: 302-311. [crossref]

40. Reeves S, Zwarenstein M, Goldman J, Barr H, Freeth D, et al. (2010) The effectiveness of interprofessional education: Key findings from a new systematic review. J Interprof Care 24: 230-41. [crossref]

41. Morse JM, Barret M, Olson K, Mayan M, Spiers J (2002) Verification strategies for establishing reliability and validity in qualitative research. Int J Qual Methods 1: $13-22$ 